\title{
Reinforcement and prestressing systems of concrete at the execution of structural elements
}

\author{
P.Bratu ${ }^{1}$, G. De Marco ${ }^{2}$ and C. Alexandru ${ }^{3}$ \\ ${ }^{1}$ ICECON SA, Bucharest, Romania \\ ${ }^{2}$ CA-TI Carnica Tiranti SRL, Roverdo in Piano, Italy \\ ${ }^{3}$ ICECON SA, Structural Dynamics and Seismic Behaviour, Bucharest, Romania
}

\begin{abstract}
This research presents the consolidation, stabilization and fixing system of anchors with protected long strands joined together in soil, by injecting grout with special additives.

Dynamic response to earthquakes, in case of anchoring system with strands must be able to reach high allowable values of total displacement (elongation of strands) in order to achieve an adequate degree of stability of ground massive.
\end{abstract}

\section{Introduction}

Consolidation of the natural soil in order to avoid slipping is the process that is undertaken effectively with anchors with long steel strands and that form a bulb at the end of the embedded attachment.

For a versant are used more anchors with length of at least $10 \mathrm{~m}$, and a density distribution such that static load could be taken over.

In case of earthquake, the anchors behaviour, when the earthquake acceleration for the first vibration mode is $\mathrm{a}(\mathrm{t})=\mathrm{a}_{0} \sin \omega \mathrm{t}=\ddot{\mathrm{u}}$,one must consider the working between anchor and equivalent support mass.

This article presents the capacity to resist with elastic elongation to seismic action.

\section{Dynamic model}

Figure 1 shows the whole consolidation with a single steel strand length $\mathrm{L}$, which is fixed by a bulb in A and in B fix a plate taking over the mass $\mathrm{m}$ of the slope. In case of a horizontal seismic motion $\mathrm{a}=\ddot{\mathrm{u}}=\mathrm{a}_{0} \sin \omega \mathrm{t}$, the anchor has as elastic element the steel strand and should take the inertial force $\mathrm{F}_{\mathrm{i}}=\mathrm{m} \cdot \mathrm{a}$. The position of strand 1 inside a protective pipe 2 , as well as the existence of fixing mortar 3 there. In this space there is oil for the cable that makes the linear viscous force evident. The dynamic model is in figure 2 where $\mathrm{k}, \mathrm{c}$ and $\mathrm{m}$ are constant.

The motion equation of mass $\mathrm{m}$ is:

$\mathrm{m} \ddot{\mathrm{x}}=\mathrm{E} \frac{\pi \mathrm{d}_{1}^{2}}{4} \cdot \frac{\mathrm{n}}{2}$

or numeric $\mathrm{k}=5 \cdot 10^{5} \mathrm{~N} / \mathrm{m}$.

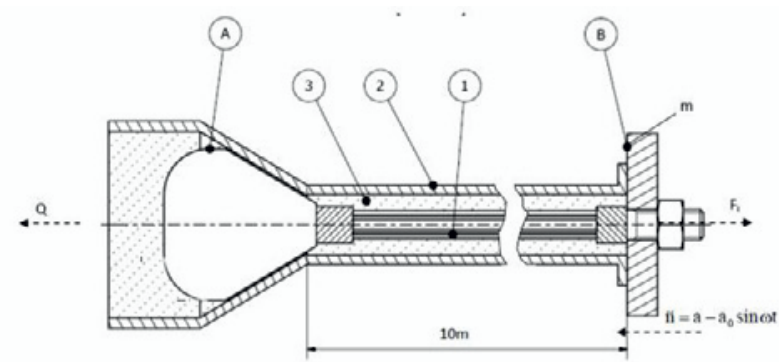

Fig. 1.

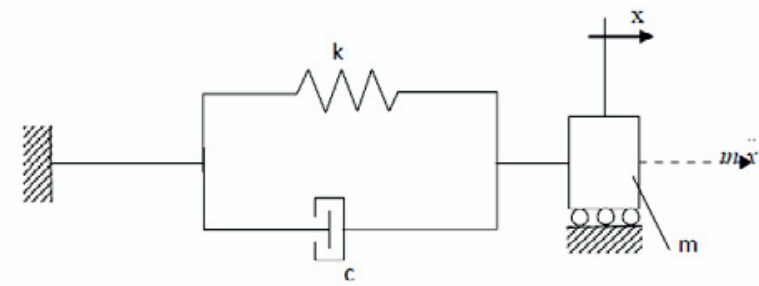

Fig. 2. Dynamic model

The mass o the consolidated part for one strand is $\mathrm{m}=10 \mathrm{t}$, and its own pulsation $\mathrm{p}_{\mathrm{x}}=\sqrt{\frac{\mathrm{k}}{\mathrm{m}}}$ or $\mathrm{p}_{\mathrm{x}}=7 \mathrm{rad} / \mathrm{s}$ and $\mathrm{f}_{\mathrm{x}}=1,125 \mathrm{~Hz}$.

In case of earthquake with period $\mathrm{T}=4 \mathrm{~s}, \mathrm{f}=\frac{1}{4}$, and $\omega=\frac{2 \pi}{4}$ and $\mathrm{a}_{0}=2,5 \mathrm{~m} / \mathrm{s}^{2}$ we have $\Omega=\frac{\omega}{\mathrm{p}_{\mathrm{x}}}=\frac{\pi^{4}}{2 \cdot 7}=0,22$.

The inertial force that is applied to the mass $\mathrm{m}$ is

$\mathrm{F}_{\mathrm{i}}=10^{4} \cdot 2,5=25 \cdot 10^{3} \mathrm{~N}$

and strand maximum strain will be: 
$\Delta_{\max }=\frac{\mathrm{F}_{\mathrm{i}}}{\mathrm{k}}=\frac{25 \cdot 10^{3}}{5 \cdot 10^{5}}=5 \cdot 10^{-2} \mathrm{~m}=50 \mathrm{~mm}$

with specific strain $\varepsilon=\frac{1005 \cdot 1000}{1000} \cdot \frac{\mathrm{cm}}{\mathrm{cm}}=0,5 \%$.

The strand stress will be:

$\sigma=\varepsilon \cdot \mathrm{E}$

or

$\sigma=\frac{0,5}{100} \cdot 2,1 \cdot 10^{5}=1000 \frac{\mathrm{N}}{\mathrm{mm}^{2}}<1200 \mathrm{~N} / \mathrm{mm}^{2}$.

The displacement amplitude at seismic motion for fundamental mode $\quad \mathrm{a}=\mathrm{a}_{0} \sin \frac{\pi}{2} \mathrm{t}$, with $\mathrm{m}=10 \mathrm{t}, \mathrm{k}=5 \cdot 10^{5} \mathrm{~N} / \mathrm{m}$,

$c=5 \cdot 10^{4} \frac{\mathrm{Ns}}{\mathrm{m}}, \mathrm{a}_{0}=2,5 \mathrm{~m} / \mathrm{s}^{2}$, it is:

$\mathrm{A}=\frac{\mathrm{u}_{0} \mathrm{~m}}{\sqrt{\left(\mathrm{k}-\mathrm{m}^{2}\right)^{2}+\mathrm{c}^{2} \omega^{2}}}$

We mark $\Omega=\frac{\infty}{p_{x}}$ and we have:

$\mathrm{A}(\Omega, \xi)=\frac{\mathrm{u}_{0} \mathrm{~m}}{\mathrm{k} \sqrt{\left(1-\Omega^{2}\right)^{2}+(2 \xi \Omega)^{2}}}$

Because $\frac{\mathrm{c}^{2} \omega^{2}}{\mathrm{k}^{2}}=\frac{\mathrm{c}^{2} \omega^{2}}{\mathrm{mp} \mathrm{p}_{\mathrm{x}}^{2} \mathrm{k}}=\frac{2 \mathrm{c}^{2}}{2 \cdot \mathrm{m} \cdot \mathrm{mp}^{2}} \cdot\left(\frac{\omega}{\mathrm{p}}\right)^{2}$, so

$\frac{\mathrm{c}^{2} \omega^{2}}{\mathrm{k}^{2}}=4\left(\frac{\mathrm{c}}{2 \mathrm{mp}}\right)^{2} \Omega^{2}$

Critical damping fraction $\xi$ is:

$\xi=\frac{c}{c_{r}}=\frac{c}{2 m p}$

or

$\xi=\frac{5 \cdot 10^{4}}{2 \cdot 10^{4} \cdot 7}=0,35$

Therefore from (6) we obtain the value of amplitude A for $\Omega=0,22$ and $\xi=0,35$ :

Critical damping fraction $\xi$ is:

$\xi=\frac{\mathrm{c}}{\mathrm{c}_{\mathrm{r}}}=\frac{\mathrm{c}}{2 \mathrm{mp}}$

or

$\xi=\frac{5 \cdot 10^{4}}{2 \cdot 10^{4} \cdot 7}=0,35$

Therefore from (6) we obtain the value of amplitude A for $\Omega=0,22$ and $\xi=0,35$ :

$A=\frac{2,5 \cdot 10^{4}}{\sqrt{\left(1-0,22^{2}\right)^{2}+(2 \cdot 0,35 \cdot 0,22)^{2}}}=52 \cdot 10^{-3} \mathrm{~m}$

The dissipated energy in the integrally joined srandtube system, when the harmonic deformation occurs with amplitude A and pulsation $\omega=0.5 \pi \mathrm{rad} / \mathrm{s}$, can be calculated as follows

$\Delta \mathrm{w}_{\mathrm{d}}=\pi \mathrm{c} \omega \mathrm{A}^{2}$

or

$\Delta \mathrm{w}_{\mathrm{d}}=\pi \cdot 5 \cdot 10^{4} \cdot 0,5 \pi \cdot 52^{2} \cdot 10^{-6}=676 \mathrm{~J}$

Taking into account that the hysteretic energy loss factor $\eta=\frac{1}{2 \pi}=0,156$, where $2 \xi_{\mathrm{eq}}=0,156$ or $\xi_{\text {eq }}=0,078$ different from $\xi=0,35$

Taking into account that $\eta=\frac{x \oplus}{\mathrm{k}}$, we have:

$\eta=\frac{c}{2 m p} \cdot 2 \Omega$

where $\eta=2 \xi_{\text {eq }}$

$\eta=2 \xi \Omega=2 \xi_{\mathrm{eq}}$

and where

$\xi_{\mathrm{eq}}=\xi \cdot \Omega$

represent the damping equivalent with the viscous one and has the meaning of hysteretic damping.

represent the damping equivalent with the viscous one and has the meaning of hysteretic damping.

We find that $\xi=\frac{c}{2 \sqrt{\mathrm{km}}}$ is the structural parameter of the system and it is dependent on the physical quantities $\mathrm{m}, \mathrm{c}, \mathrm{k}$ without the influence of dynamic vibration regime for instance $\omega$ or $\Omega$.

For $\Omega \neq 0$, namely under harmonic vibration regime, the structural equivalent damping depends essentially of pulsation $\omega$ and $\Omega$.

At resonance, for $\Omega=1$, critical damping fraction $\xi$ is equal with structural damping $\xi_{\text {eq }}$ ie $\xi_{\mathrm{eq}}^{\mathrm{rez}}=\xi^{\mathrm{rez}}=\frac{\mathrm{c}}{2 \mathrm{~m} \omega_{\mathrm{rez}}}$.

\section{Bearing capacity}

Dynamic force $F_{i}$ of seismic movement must be taken by the strand-bulb system in order to keep in contact with the allowed deflection. So, in dynamic regime we have to determine the force from bulb $\mathrm{Q}=\mathrm{Q}_{0} \sin (\omega \mathrm{t}-\varphi)=\mathrm{kx}+\mathrm{c \dot {x }}$

In this case, the transmitted force is determined on the relation transmissibility as follows:

$\mathrm{Q}_{0}=\mathrm{F}_{0} \mathrm{~T}(\Omega, \xi)$

where

$\mathrm{T}(\Omega, \xi)=\sqrt{\frac{1+(2 \xi \Omega)^{2}}{\left(1-\Omega^{2}\right)^{2}+(2 \xi \Omega)^{2}}}$

Substituting in (10) the values of $\Omega=0,22, \xi=0,35$, we obtain $\mathrm{T}(\Omega, \xi)=1,05$ 
$\mathrm{Q}_{0}=\mathrm{ma}_{0} \mathrm{~T}(\Omega, \xi)=10^{4} \cdot 2,5 \cdot 1,05=26250 \mathrm{~N}$,

ie transmitted force $\mathrm{Q}_{0}=26250 \mathrm{~N}>\mathrm{F}_{0}$, where $\mathrm{F}_{0}=25000$ N.

Figure 3 presents the curve family $\mathrm{T}(\Omega, \mathrm{f})$ for $\Omega=0, \ldots . .5$ with discrete values $\xi=0,15 ; 0,25 ; 0,35$.

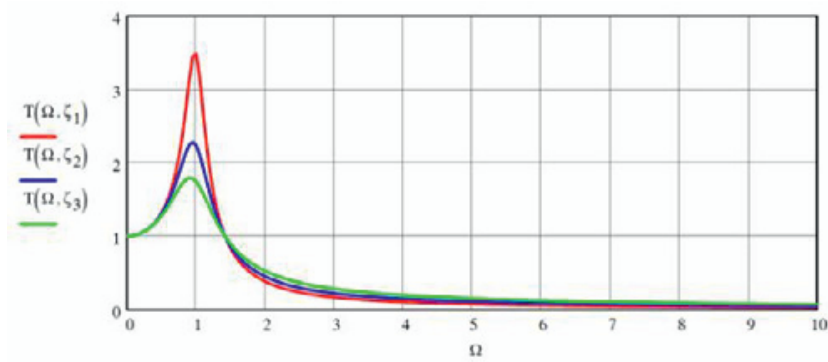

Fig 3 Curve family $\mathrm{T}(\Omega$, f) for $\Omega=0, \ldots . .5$ with discrete values $\xi=0,15 ; 0,25 ; 0,35$

The optimization condition of force $\mathrm{Q}_{0}$ results only for $\mathrm{T}<1$, ie $\Omega>\sqrt{2}$.

In this case, we choose $\Omega_{2}=2$ for $\mathrm{T}_{2}(2 ; 0,35)=0,52$ so we have:

$\mathrm{Q}_{0}^{\text {optim }}=\mathrm{ma}_{0} \mathrm{~T}_{2}=10^{4} \cdot 2,5 \cdot 0,52=1,3 \cdot 10^{4}$

$\mathrm{Q}_{0}^{\text {optim }}=1300 \mathrm{~N}<\mathrm{F}_{0}$.

In this case, strands has to be more elastic, ie $\Omega=2=\frac{\infty}{2}$, so

$\mathrm{p}_{2}=\frac{\infty}{2}=\sqrt{\frac{\mathrm{k}_{2}}{\mathrm{~m}}}$

Results $\mathrm{k}_{2}=\frac{1}{2} \mathrm{~m} \omega^{2}=\frac{1}{4} 10^{4} \frac{\pi^{2}}{4}=0,61 \cdot 10^{4}$

So $\mathrm{p}_{2}=\sqrt{\frac{0,61 \cdot 10^{4}}{10^{4}}}=0,78 \mathrm{rad} / \mathrm{s}$ from $\mathrm{p}_{1}=7 \mathrm{rad} / \mathrm{s}$.

Figure 4 shows the new configuration of curves $\mathrm{p}_{1}=7 \mathrm{rad} / \mathrm{s}, \quad \xi=0,35$ and at $\mathrm{p}_{2}=0,78 \mathrm{rad} / \mathrm{s}$, $\xi=0,35$ for $\omega=\frac{\pi}{2}=1,57 \mathrm{rad} / \mathrm{s}$.

So we have,

$\mathrm{T}_{1}\left(\frac{\omega}{\mathrm{p}_{1}}, \xi\right)=\sqrt{\frac{1+\left(2 \xi \frac{\omega}{\mathrm{p}_{1}}\right)^{2}}{\left[1-\left(\frac{\omega}{\mathrm{p}_{1}}\right)^{2}\right]^{2}+\left(2 \xi \frac{\omega}{\mathrm{p}_{1}}\right)^{2}}}$

or

$\mathrm{T}_{1}\left(\frac{\omega}{\mathrm{p}_{1}}, \xi\right)=\sqrt{\frac{1+0,01 \cdot \omega^{2}}{\left(1-0,02 \omega^{2}\right)^{2}+0,01 \omega^{2}}}$
$\mathrm{T}_{2}\left(\frac{\omega}{\mathrm{p}_{2}}, \xi\right)=\sqrt{\frac{1+0,8 \omega^{2}}{\left(1-1,64 \omega^{2}\right)^{2}+0,8 \omega^{2}}}$

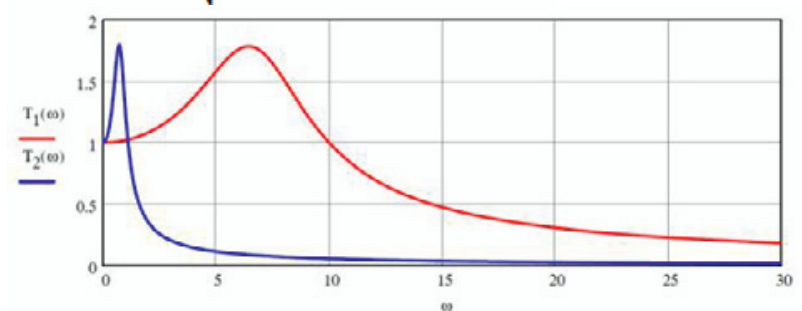

Fig 4 Curve family for $\omega=\frac{\pi}{2}$.

We note that the stiffness $\mathrm{k}_{2}=0,6 \cdot 10^{4} \mathrm{~N} / \mathrm{m}$ it is less then stiffness $\mathrm{k}_{1}=5 \cdot 10^{5} \mathrm{~N} / \mathrm{m}$ as 80 times, so less wires $\mathrm{n}=3$ with diameter $\mathrm{d}=0,5 \mathrm{~mm}$, so the deformation would be $\Delta=4 \mathrm{~mm}$. As a result the solution is not possible for $\Omega<1$, where $\mathrm{T}>1$, so we'll have in bulb always $\mathrm{Q}_{0}>\mathrm{F}_{0}$.

\section{Conclusions}

The anchors system with steel strands having lengths of over $10 \mathrm{~m}$ secure the fixation of slopes in static and dynamic regime to seismic forces.

Transmitted force to the bulb can be $5 \% \ldots 25 \%$ bigger than the excitation force, with low elongation.

The structural damping of the system $\xi_{\text {eq }}<\xi$ for $\Omega<1$, what makes that during the cyclic loading the dissipated energy is relatively low and without external heat transfer.

Anchor strength is provided both by good elongation and relatively low stiffness, as well as by rigid fixing of the bulb with grout fuelled under pressure into the tube locations.

\section{References}

1. C. Mircea, Gh. Petsovay, H. Nicoară, Calculul neliniar al elementelor de beton armat și precomprimat. Cluj-Napoca, Star, (2004).

2. P. Bratu, Analiza structurilor elastice. Comportarea la actiuni statice si dinamice, Editura IMPULS, pp 425, Bucuresti, (2011)

3. M. Dolce, F.C. Ponzo, A. DiCesare, G. Arleo, Progetto di Edifici con Isolamento Sismico, Iuss Press, Pavia, Italy, (2010).

4. L. Meinovitch, Dynamics and Control of Structures, New York, (1990).

5. Al. Gheorghiu, Conceptii moderne in calculul structurilor. Ed. Tehnică, București, (1981).

6. I.Magheti, M. Savu, Teoria și practica vibrațiilor mecanice. EDP, (2007). 